\title{
Barriers and facilitators of exercise experienced by cancer survivors: A mixed methods systematic review
}

Briana K. Clifford ${ }^{1,2}$, David Mizrahi1,3, Carolina X. Sandler ${ }^{2,4}$, Benjamin K. Barry1,5, David Simar1, Claire E. Wakefield ${ }^{3,6}$, David Goldstein7.

${ }^{1}$ School of Medical Sciences, UNSW Medicine, UNSW Sydney, Australia;

${ }^{2}$ National Centre for Cancer Survivorship, UNSW Sydney, Australia;

${ }^{3}$ Behavioural Sciences Unit, Kids Cancer Centre, Sydney Children's Hospital, Sydney, Australia;

${ }^{4}$ UNSW Fatigue Clinic, UNSW Sydney, Australia;

${ }^{5}$ Neuroscience Research Australia, Randwick, Australia;

${ }^{6}$ Discipline of Paediatrics, School of Women's and Children's Health, UNSW Medicine, UNSW Sydney, Australia;

${ }^{7}$ Department of Medical Oncology, Prince of Wales Hospital, Randwick, Australia.

Corresponding author: Briana Clifford, School of Medical Sciences, UNSW Medicine, UNSW Sydney, Level 2, Wallace Wurth Building, Sydney, Australia, 2052. 


\section{Abstract}

PURPOSE: Exercise has been shown to improve the health and well-being of people who have survived cancer. Yet, less than $40 \%$ of cancer survivors in Australia meet the recommended 150 minutes of moderate-intensity physical activity per week. Our objective was to systematically review the literature regarding barriers, facilitators and preferences for exercise for survivors of cancer.

METHOD: MEDLINE, EMBASE, CINAHL, PsycINFO and Scopus were searched for qualitative and quantitative articles addressing barriers, facilitators and preferences for exercise in cancer survivors. Quality assessment was performed by two independent reviewers using the Mixed Methods Appraisal Tool. Thomas and Harden's method of thematic synthesis was used to amalgamate qualitative data while descriptive statistics were used to collate quantitative data.

RESULTS: Nineteen studies were included (9 qualitative and 10 quantitative). Persisting treatmentrelated side effects was the most commonly reported barrier to initiating or maintaining exercise, followed by lack of time and fatigue. The most common facilitators of exercise were gaining a feeling of control over their health as well as managing emotions and mental well-being, while the preferred method of exercise was walking. We also identified a lack of useful information provided to survivors regarding exercise.

CONCLUSION: Treatment-related side effects, lack of time, and fatigue were key barriers to exercise for survivors of varied cancer types. Insufficient patient education may contribute to the belief that exercise is not helpful when experiencing side effects of treatment, including fatigue. Identifying barriers and facilitators leads to improved support and education from health professionals which is required to provide safe and effective exercise recommendations for survivors.

Keywords: Cancer; Survivor; Physical activity; Exercise; Barriers; Facilitators 
Improvements in detection and treatment of cancer, combined with the ageing of the population have contributed to the growing number of cancer survivors [1,2]. Those who survive their cancer experience a range of adverse effects from the cancer and its treatment, including fatigue, disrupted sleep, neuropathy, chronic pain, loss of physical function, impaired cognition, depression and anxiety, and decreased quality of life [3-5]. Loss of lean muscle mass accompanied by a decrease in muscle strength and endurance also impacts heavily on the physical functioning of cancer patients and survivors [6].

A meta-analysis of 14 studies, including 1047 participants (Intervention $n=522$; control $n=525$ ) and conducted in 2016, found that strength exercises were effective in improving lower limb muscle strength and function, as well as preventing the loss of lean body mass in patients undergoing chemotherapy [7]. Similarly, a meta-analysis of 34 studies with a total of 641 participants investigated the effect of aerobic, resistance and combination exercise interventions on objective measures of physical function in cancer survivors[8]. They reported significant improvements in peak oxygen consumption, peak power output, six-minute walk distance, bench press weight, leg press weight and right handgrip strength as well as the physical and social functioning domains of quality of life. Additional studies also suggest that higher levels of physical activity are associated with decreased all-cause mortality as well as cancer-specific mortality in breast, colorectal, prostate, lung and ovarian cancer survivors [9-12]. A review of 71 prospective cohort studies showed a minimum of 2.5 hours per week of moderate intensity physical activity led to a significant decrease in cancer mortality (13\%), while high intensity physical activity had a $27 \%$ reduction [13]. Furthermore, A recent systematic review found that 17 out of the 30 reviewed studies reported a significantly lower risk of cancer specific mortality with higher exercise levels as well a significantly lower risk of allcause mortality among patients with higher exercise levels [14].

Despite the robust evidence of the positive effects of exercise for cancer survivors, most cancer survivors are not meeting the recommended physical activity guidelines of 150 minutes per week of 
moderate-to-vigorous aerobic physical activity, as well as 2-3 strength training sessions per week [15-17]. While this may be comparable to the general population[18,16], cancer survivors have an increased need for the beneficial effects of exercise given the increased co-morbidities experienced in this population [14]

While exercise is highly beneficial, cancer survivors face a range of factors that may impede or facilitate their participation in physical activity. Identifying key barriers to exercise may help clinicians overcome these issues by providing support and education, as well as access to reliable sources of information. A diverse body of literature exists, providing both qualitative and quantitative data which identifies barriers and facilitators of exercise for cancer survivors. However, to this point no studies have integrated this information. The aim of this paper is to systematically review the qualitative and quantitative literature regarding barriers and facilitators for exercise experienced by cancer survivors. The secondary aim is to review the exercise preferences of cancer survivors.

\section{Methods}

Search strategy

We registered with PROSPERO (Registration number 2016: CRD42016036620) in March 2016 after the completion of the literature search and prior to the selection of articles for extraction of data. The systematic literature search was conducted using five databases (MEDLINE/Pubmed, EMBASE, CINAHL Scopus and PsycInfo) for appropriate papers until February 2016. A professional scientific librarian helped with the development of the search terms which included (neoplasm OR cancer OR malignancy) AND (exercise OR physical activity OR exercise therapy OR motor function OR kinesiotherapy) AND (survivor OR survivors OR survivorship).

Inclusion and exclusion criteria 
Peer reviewed papers published between the $1^{\text {st }}$ of January 2000 and February 2016 were included in this search. Studies containing qualitative or quantitative data pertaining to barriers or facilitators of exercise initiation in people who had undergone treatment for cancer were included. Barriers to exercise are described as patient reported reasons for not exercising or adhering to an exercise intervention, while facilitators of exercise are reasons described by survivors which motivate them to initiate exercise or adhere to an exercise program. This may include their beliefs surrounding the risks and benefits of exercise. Papers were excluded if they did not meet the primary research objective, that is that review of the content did not identify any data pertaining to barriers and/or facilitators of exercise in cancer survivors. Articles were not excluded if the data presented supporting the absence of effect or even a negative effect of the exercise program on the primary outcomes presented in these articles. Qualitative studies were included if they reported on barriers or facilitators of exercise using open discussion, focus groups and semi-structured interviews. Articles were excluded if the participant cohort was outside of $18-80$-year age range, if participants had metastatic disease or were still undergoing treatment. Participants undergoing adjuvant hormone therapy were not excluded. Studies including participants with metastatic disease were excluded unless they had performed a sub analysis of patients who had completed treatment or were considered 'cancer-free'. Adult survivors of childhood cancer were included if they were at least 5-years post cancer treatment.

\section{Selection procedure}

All titles were initially screened (BC), removing duplicate references, conference abstracts and unpublished dissertations. All titles were then screened by two independent reviewers (DM; CXS). Any discrepancies were discussed and resolved with a third reviewer (BB). The same screening process was repeated for abstract and full text screening.

Quality assessment (risk of bias) 
Study quality was assessed using the Mixed Methods Appraisal Tool (MMAT-Version 11). This tool was developed for the appraisal of methodological quality of qualitative, quantitative and mixed methods studies [19-21]. The tool has been used for quality assessment in similar mixed method systematic reviews $[22,23]$. Each study included in the quality assessment was evaluated by two independent reviewers (DM; CXS) with any discrepancies mediated by a third reviewer (BC). Each study was assigned a score based on the number of criteria met ( $25 \%$ - one criteria met; $100 \%$ all criteria met). Studies were excluded from the review if they scored less than $75 \%$ for quality, meaning that they fulfilled a maximum of only 2 of 4 criteria. Low scores on the MMAT have been used previously as a basis for excluding low quality studies [21].

\section{Data extraction}

Initial extraction of data relating to demographics and study design was consistent across qualitative and quantitative papers. A data extraction form was created and used to gather demographic and study design information from all papers. Thomas and Harden's thematic synthesis was used to categorise barriers and facilitators into themes across qualitative studies [24]. The frequency of barriers, facilitators and preferences in quantitative studies were then tallied. Barriers, facilitators and preferences from qualitative and quantitative studies were integrated by combining similar themes.

A weighted sum was calculated to permit a synthesis of barriers, facilitators and preferences identified across studies. Following the categorisation of barriers, facilitators and preferences across included studies, each of these factors was assigned a weighting according to its identified importance. A 3-point scale was developed and applied to the data of each study. Factors that were most frequently reported, or were identified as most pertinent by the study authors, were assigned a score of 3; those factors that were of moderate frequency or pertinence were assigned a score of 2 , and those with the lowest frequency of reporting or emphasis of pertinence were assigned a score of 1. If a barrier, facilitator or preference was not reported it was assigned a score of 0 . A default 
score of 2 was assigned for barriers, facilitators or preferences that were not able to be rated, but were reported. Total scores were summed to determine the overall importance of any one barrier, facilitator or preference across all included studies.

In quantitative studies, if a given barrier, facilitator or preference had been reported by a large proportion of participants $(>50 \%)$, or was rated as being of high importance, it would be assigned a score of 3 . If it had only been reported by a small proportion of participants $(<25 \%)$ it was assigned a 1. In qualitative studies, if a given barrier, facilitator or preference had been deemed to be of high importance by the study authors then it was assigned a 3 and if it had been deemed to be of negligible importance it was assigned a 1. Three independent reviewers (BC; DM; CXS) assigned scores to each of the barriers, facilitators and preferences encountered throughout all included studies. As seen in Figure 2, the scale represents the highest possible score that could be obtained by each barrier if it was reported in every publication and considered of high importance (barriers to exercise $=$ maximum score of 60; facilitators of exercise $=$ maximum score of 30$)$. An inter-rater reliability $\boldsymbol{\kappa}$ of 0.84 for quantitative studies and 0.85 for qualitative studies was calculated, suggesting a high level of agreement amongst reviewers [25]. Any discrepancies were resolved by a fourth reviewer (BB).

\section{Results}

Search results and overview of studies included

The initial search yielded 5438 articles (Figure 1). 4723 articles were removed based on the inclusion/exclusion criteria. 715 were read in full, with 673 removed due to not distinguishing between survivors being on and off treatment, having participants $<18$ years of age, or the paper not meeting the primary research objective (i.e. not recording any data pertaining to barriers and/or facilitators of exercise in cancer survivors). The 42 remaining articles underwent quality assessment with the MMAT. 23 were removed due to inadequate quality (MMAT $<75 \%$ ), and 19 studies were 
included in this systematic review (a summary of study quality for all 42 studies can be found in supplementary materials).

Eleven quantitative and nine qualitative studies, published between January 2005 and February 2016, were included and study characteristics can be found in Table 1. Seven studies were conducted in survivors of breast cancer, five in prostate cancer, three in colorectal cancer, and four studies conducted in a mixed population with a representative spread of other common cancers. While all participants had completed treatment, the range in time from treatment was broad, ranging from 3 weeks after treatment completion to over 6-years post treatment.

\section{Barriers and facilitators of exercise}

The reported barriers and facilitators were consistent across quantitative and qualitative studies, with the most common barriers to exercise being treatment-related side effects, lack of time, and fatigue (Fig. 2). Chronic diarrhoea was frequently reported as a barrier to exercise for colorectal cancer cohorts, and colostomy bags were a barrier specific to their cancer treatment. Breast cancer survivors reported lymphedema, shoulder stiffness, and myalgia and arthralgia (described as "aches and pains") as treatment-related side effects, and prostate cancer survivors reported incontinence as a treatment-related side effect that hindered exercise participation. Among both qualitative and quantitative studies there was no separation between fatigue as a treatment-related side effect and fatigue unrelated to cancer treatment. Participants reported treatment-related side effects as a barrier separately to fatigue as a barrier, warranting a division between the two in this review. No distinction within the studies was made between the degree of fatigue experienced, and whether this fatigue interrupted function. Phrases that were used to identify fatigue as a barrier included 'fatigue', 'too tired' and 'not enough energy', potentially encompassing a range of symptoms, some more disabling than others. Not knowing what do to or a lack of information was a significant barrier to initiating and maintaining exercise noted in this review. Important issues included a lack of information from health professionals and a lack of knowledge surrounding exercise type and 
intensity that is safe and effective. The strongest facilitators of exercise were improved physical health, improved mental well-being, gaining a sense of control over their health and lives, and social benefits of exercise (Fig. 2).

\section{Exercise Preferences}

A limited number of the included studies collected information regarding cancer survivors' preferences for exercise $(5 / 19,26 \%$ of studies). When addressing preferences for exercise it was found that survivors preferred walking as the type of exercise, at a moderate intensity, beginning either immediately after completing treatment or 3-6-months after treatment completion. When receiving exercise counselling or advice, survivors preferred to receive information face-to-face but with the option to exercise at home either supervised or unsupervised. 


\section{Discussion}

This systematic review is the first to comprehensively review barriers and facilitators of exercise for cancer survivors, encompassing both qualitative and quantitative studies. Cancer survivors face a range of barriers when initiating exercise, some of which are experienced by the general population, but also others that are specific to their cancer treatment[26]. We identified the key barriers to exercise, which were treatment-related side effects, lack of time, and fatigue. We further established the key facilitators of exercise including improved physical health, improved mental wellbeing, gaining control and the social benefits of exercise. The most pertinent barriers and facilitators were consistently reported across qualitative and quantitative studies and these were rated similarly in terms of importance in each study. Barriers to exercise that have been identified in large $\underline{\text { Randomised controlled trials are consistent with the findings of this review. Lack of time, fatigue and }}$ treatment related side effects are reported as the most pertinent barriers to exercise in an RCT setting as they are in a community setting[27]. We established that the preferred mode of exercise was walking at a moderate intensity after the completion of treatment.

Treatment-related side-effects were the most reported barriers to exercise. This general descriptor encompassed a host of side effects related to cancer treatment. It is reported that some side-effects of treatment may resolve quickly while other late effects of treatment may persist or not develop until further into survivorship [28]. This may create a large variance in the treatment-related sideeffects experienced by each individual and the impact that this may have on their ability to exercise. Fatigue is one of the most commonly reported side effects of cancer treatment [29], and therefore predictably, was reported frequently as a barrier to exercise. Cancer-related fatigue has been shown to affect approximately $70 \%$ of patients who have undergone chemotherapy or radiotherapy [29]. It undergoes a natural history of decreasing severity over the first 12 months after treatment, with a smaller proportion of survivors experiencing persisting fatigue after this point $[30,31]$. In this context, exercise has been shown to be an effective moderator of cancer-related fatigue and to play 
an important role in improving patient function [32]. Similarly, it ameliorates many other common treatment-related side effects, including decreased quality of life, reduced cardiorespiratory fitness and physical functioning $[33,34]$. However, exercise as a treatment for fatigue requires support and education to inform patients of the most safe and effective way to start exercising, with behavioural change strategies required to improve adherence [35]

Lack of time was another prominent barrier to exercise, consistent with reports for a range of chronic diseases and in healthy populations $[36,37]$. This is a difficult barrier to address, but possible solutions include behaviour change strategies to elevate the priority of exercise [35,38], readily accessible exercise facilities $[39,40]$ and even high-intensity exercise options that may be more time efficient. High intensity interval training (HIIT) is effective at improving aerobic capacity and decreasing metabolic and cardiovascular risk in chronic disease populations [41] and offers a more time efficient option for exercise training [42]. HIIT has been shown to be tolerated by cancer survivors and preliminary studies show positive effects, comparable to traditional exercise methods[43] however more research is required to elicit the clinical benefits of HIIT for cancer survivors [42,43]. Motivational interviewing may have a role in overcoming common lifestyle-related barriers such as time management and has been shown to be effective in increasing exercise adherence [44]. While access to exercise counselling services may be available to a limited extent throughout hospitals, cancer survivors report limited guidance on how to access exercise counselling and program services [45]. Notably, the greatest behaviour change comes with face-to-face delivery of counselling and supervision of exercise services [46]. However, recent meta-analyses of exercise interventions in cancer populations have shown a considerable effect of telephone or email counselling services. This may represent a more affordable and feasible avenue of support for some survivors $[46,47]$.

Much research has been conducted identifying cancer diagnosis as a potentially constructive experience in terms of a 'teachable moment' [48]. This refers to a chance to provide support and 
education to survivors that may impact their lifestyle choices, decreasing their risk of suffering from common comorbidities associated with cancer survivorship [49]. This significant proportion of survivors reporting a lack of knowledge surrounding exercise may highlight a gap in relation to exercise information as part of the supportive care being delivered after the completion of treatment. Alternatively, while information may be available, more guidance on where and how to access this information from health professionals and the counselling approaches previously discussed may be of benefit [45].

traditional family caregiving roles and lack of support from family were perceived as significant barriers to exercise amongst a cohort of Mexican American, Chinese American and Korean American breast cancer survivors. This was not commonly reported amongst other studies and may provide some insight into cultural differences in attitudes towards exercise. Similarly, this article highlights that cultural differences may exist in relation to health behaviours and further research should be conducted to identify barriers and facilitators of exercise for people of non-white Caucasian, cultural backgrounds[50].

None of the included studies addressed differences in barriers and facilitators in relation to aerobic exercise vs resistance exercise. These two differing types of exercise might in fact pose different obstacles for cancer survivors. While some reported barriers, such as, "no facilities" and "don't know what to do" may be more specific to resistance exercises rather than common aerobic exercise such as walking, no distinction between the two types of exercise was made. Beneficial effects of $\underline{\text { resistance exercise have been shown in the cancer survivor population [51,52]. Our present results }}$ show that survivors express a clear preference for walking as their preferred method of exercise. This suggests that efforts to determine specific barriers to aerobic or resistance exercise may identify $\underline{\text { strategies to increase participation in resistance exercise in this population. }}$ 
The facilitators of exercise that were most commonly reported were improved physical health, improved mental well-being and a sense of gaining control over their health. This is consistent with the literature, which shows that exercise improves physical function and reduces pain and fatigue in cancer survivors, which in turn improves quality of life and feelings of well-being [53]. Another identified facilitator was the social benefit of exercise, which suggests that accessible, supervised or group exercise options may facilitate the formation of healthy exercise habits in cancer survivors [54].

While the most pertinent barriers and facilitators to exercise were consistent across studies of both qualitative and quantitative nature, some barriers were identified in qualitative studies such as 'don't like to sweat' and 'not the sporty type', which are not typical questions included in validated quantitative questionnaires. This highlights the importance of both qualitative and quantitative literature in the context of beliefs surrounding exercise. However, it is noted that the number of participants reporting these barriers were very small.

Strengths of this review were the registration of the protocol with PROSPERO before data extraction and analysis occurred and the rigorous dual screening process for inclusion and quality assessment of all studies. The inclusion of both qualitative and quantitative literature allowed a comprehensive understanding of patient beliefs regarding barriers and facilitators of exercise not limited to quantifiable measures. The MMAT is recognised as a unique tool for assessing qualitative, quantitative and mixed methods literature for mixed methods reviews, which allows for the assessment of studies with diverse designs [55]. While the utility of this tool is clear, there are some limitations surrounding interpretation and subjectivity when employing the MMAT. Previous studies have found reduced inter rater reliability when assessing qualitative literature, which highlights the complexity of using critical appraisal tools to assess studies of this design [21]. A recent review further examined the reliability of the tool and found it to be more reliable when a discussion took place to clarify the meaning of some questions, in particular, questions relating to context and 
setting of data collection before appraising the studies. [55]. In the current study, the meaning of these questions and statements was discussed between all reviewers before critical appraisal of the literature.

The research group opted to use a quantifiable scale to rate the importance of each barrier across each of the included studies. While this novel approach may be viewed as a limitation of the study, it is noted that the procedure was performed to ensure reliability with parallel reviewers and the use of a Kappa analysis to ensure consistency of scoring. Broadly, the use of quantifiable scales within qualitative or mixed methods literature, or "quantitizing" qualitative data [56], is supported by past research which highlights the underutilization of numbers in qualitative research, potentially leading to a more simplistic interpretation of results [57]. Similarly, articles that have examined mixed methods approaches have advocated for more integration between qualitative and quantitative data within mixed methods studies [58].

There were several limitations in the data we reviewed, including that the cancer survivor cohorts were largely heterogeneous with survivors ranging from 3-weeks post completion of treatment up to 6.5-years post completion of treatment. Due to the mixed nature of the cohorts, no sub-analysis for cancer type or cancer treatment could be performed. It is noted that most of the studies included cohorts of predominantly white, English speaking people with limited socio-economic deprivation, which should be taken into account when interpreting results. Future directions should identify the role of motivational interviewing, education and support in overcoming barriers to exercise for cancer survivors and the feasibility of implementing these strategies in routine patient care. 


\section{Conclusion}

The greatest barriers to exercise among cancer survivors were treatment-related side-effects, lack of time, and fatigue. Insufficient patient education may facilitate the belief that exercise is not helpful when experiencing side effects of treatment, including fatigue. Similarly, improved support from health professionals may be required to provide safe and effective exercise recommendations for survivors to enable the formation of healthy exercise habits. Further research is required to establish the effect of implementing education strategies and opportunities for patients and survivors to liaise with health professionals to overcome barriers and increase exercise adherence in a cancer survivor population. 
Funding: Claire Wakefield is supported by a Career Development Fellowship from the National Health and Medical Research Council (NHMRC) of Australia (APP1067501). The Behavioural Sciences Unit is proudly supported by the Kids with Cancer Foundation.

Conflicts of Interest: Nothing to declare 


\section{References}

1. Torre LA, Bray F, Siegel RL, Ferlay J, Lortet-Tieulent J, Jemal A (2015) Global cancer statistics, 2012. CA: a cancer journal for clinicians 65 (2):87-108. doi:10.3322/caac.21262

2. Parry C, Kent EE, Mariotto AB, Alfano CM, Rowland JH (2011) Cancer survivors: a booming population. Cancer epidemiology, biomarkers \& prevention : a publication of the American Association for Cancer Research, cosponsored by the American Society of Preventive Oncology 20 (10):1996-2005. doi:10.1158/1055-9965.EPI-11-0729

3. Fallon MT (2013) Neuropathic pain in cancer. Br J Anaesth 111 (1):105-111. doi:10.1093/bja/aet208

4. McDougall GJ, Jr., Oliver JS, Scogin F (2014) Memory and cancer: a review of the literature. Archives of psychiatric nursing 28 (3):180-186. doi:10.1016/j.apnu.2013.12.005

5. Pachman DR, Barton DL, Swetz KM, Loprinzi CL (2012) Troublesome symptoms in cancer survivors: fatigue, insomnia, neuropathy, and pain. Journal of clinical oncology : official journal of the American Society of Clinical Oncology 30 (30):3687-3696. doi:10.1200/JCO.2012.41.7238

6. Barreto R, Waning DL, Gao H, Liu Y, Zimmers TA, Bonetto A (2016) Chemotherapy-related cachexia is associated with mitochondrial depletion and the activation of ERK1/2 and p38 MAPKs. Oncotarget 7 (28):43442-43460. doi:10.18632/oncotarget.9779

7. Padilha CS, Marinello PC, Galvao DA, Newton RU, Borges FH, Frajacomo F, Deminice R (2017) Evaluation of resistance training to improve muscular strength and body composition in cancer patients undergoing neoadjuvant and adjuvant therapy: a meta-analysis. Journal of cancer survivorship : research and practice 11 (3):339-349. doi:10.1007/s11764-016-0592-x

8. Fong DY, Ho JW, Hui BP, Lee AM, Macfarlane DJ, Leung SS, Cerin E, Chan WY, Leung IP, Lam SH, Taylor AJ, Cheng KK (2012) Physical activity for cancer survivors: meta-analysis of randomised controlled trials. BMJ (Clinical research ed) 344:e70. doi:10.1136/bmj.e70

9. Borch KB, Braaten T, Lund E, Weiderpass E (2015) Physical activity before and after breast cancer diagnosis and survival - the Norwegian women and cancer cohort study. BMC cancer 15:967. doi:10.1186/s12885-015-1971-9

10. Ballard-Barbash R, Friedenreich CM, Courneya KS, Siddiqi SM, McTiernan A, Alfano CM (2012) Physical activity, biomarkers, and disease outcomes in cancer survivors: a systematic review. Journal of the National Cancer Institute 104 (11):815-840. doi:10.1093/jnci/djs207

11. Zhou Y, Chlebowski R, LaMonte MJ, Bea JW, Qi L, Wallace R, Lavasani S, Walsh BW, Anderson G, Vitolins M, Sarto G, Irwin ML (2014) Body mass index, physical activity, and mortality in women diagnosed with ovarian cancer: results from the Women's Health Initiative. Gynecologic oncology 133 (1):4-10. doi:10.1016/j.ygyno.2014.01.033

12. Wang A, Qin F, Hedlin H, Desai M, Chlebowski R, Gomez S, Eaton CB, Johnson KC, Qi L, Wactawski-Wende J, Womack C, Wakelee HA, Stefanick ML (2016) Physical activity and sedentary behavior in relation to lung cancer incidence and mortality in older women: The Women's Health Initiative. International journal of cancer Journal international du cancer 139 (10):2178-2192. doi:10.1002/ijc.30281

13. Li T, Wei S, Shi Y, Pang S, Qin Q, Yin J, Deng Y, Chen Q, Wei S, Nie S, Liu L (2016) The doseresponse effect of physical activity on cancer mortality: findings from 71 prospective cohort studies. British journal of sports medicine 50 (6):339-345. doi:10.1136/bjsports-2015-094927

14. Cormie P, Zopf EM, Zhang X, Schmitz KH (2017) The Impact of Exercise on Cancer Mortality, Recurrence, and Treatment-Related Adverse Effects. Epidemiologic reviews 39 (1):71-92. doi:10.1093/epirev/mxx007

15. Schmitz KH, Courneya KS, Matthews C, Demark-Wahnefried W, Galvao DA, Pinto BM, Irwin ML, Wolin KY, Segal RJ, Lucia A, Schneider CM, von Gruenigen VE, Schwartz AL, American College of Sports M (2010) American College of Sports Medicine roundtable on exercise guidelines for cancer survivors. Medicine and science in sports and exercise 42 (7):1409-1426.

doi:10.1249/MSS.0b013e3181e0c112 
16. Tarasenko Y, Chen C, Schoenberg N (2017) Self-Reported Physical Activity Levels of Older Cancer Survivors: Results from the 2014 National Health Interview Survey. Journal of the American Geriatrics Society 65 (2):e39-e44. doi:10.1111/jgs.14589

17. Irwin ML, McTiernan A, Bernstein L, Gilliland FD, Baumgartner R, Baumgartner K, Ballard-Barbash $R$ (2004) Physical activity levels among breast cancer survivors. Medicine and science in sports and exercise 36 (9):1484-1491

18. Crombie IK, Irvine L, Williams B, McGinnis AR, Slane PW, Alder EM, McMurdo ME (2004) Why older people do not participate in leisure time physical activity: a survey of activity levels, beliefs and deterrents. Age and ageing 33 (3):287-292. doi:10.1093/ageing/afh089

19. Pluye P, Robert, E., Cargo, M., Bartlett, G., O'Cathain, A., Griffiths, F., Boardman, F., Gagnon, M.P., \& Rousseau, M.C. (2011) Proposal: A mixed methods appraisal tool for systematic mixed studies reviews. . Department of Family Medicine, McGill University, Montreal, Canada Retrieved on 5 March 2016 from http://mixedmethodsappraisaltoolpublic.pbworks.com.

20. Pluye P, Gagnon MP, Griffiths F, Johnson-Lafleur J (2009) A scoring system for appraising mixed methods research, and concomitantly appraising qualitative, quantitative and mixed methods primary studies in Mixed Studies Reviews. International journal of nursing studies 46 (4):529-546. doi:10.1016/j.ijnurstu.2009.01.009

21. Pace R, Pluye P, Bartlett G, Macaulay AC, Salsberg J, Jagosh J, Seller R (2012) Testing the reliability and efficiency of the pilot Mixed Methods Appraisal Tool (MMAT) for systematic mixed studies review. International journal of nursing studies 49 (1):47-53.

doi:10.1016/j.ijnurstu.2011.07.002

22. Massey D, Chaboyer W, Anderson V (2017) What factors influence ward nurses' recognition of and response to patient deterioration? An integrative review of the literature. Nursing open 4 (1):623. doi:10.1002/nop2.53

23. Mey A, Plummer D, Dukie S, Rogers GD, O'Sullivan M, Domberelli A (2017) Motivations and Barriers to Treatment Uptake and Adherence Among People Living with HIV in Australia: A MixedMethods Systematic Review. AIDS and behavior 21 (2):352-385. doi:10.1007/s10461-016-1598-0 24. Thomas J, Harden A (2008) Methods for the thematic synthesis of qualitative research in systematic reviews. BMC medical research methodology 8:45. doi:10.1186/1471-2288-8-45 25. McHugh ML (2012) Interrater reliability: the kappa statistic. Biochem Med (Zagreb) 22 (3):276282

26. Justine M, Azizan A, Hassan V, Salleh Z, Manaf H (2013) Barriers to participation in physical activity and exercise among middle-aged and elderly individuals. Singapore medical journal 54 (10):581-586

27. Courneya KS, Friedenreich CM, Quinney HA, Fields AL, Jones LW, Vallance JK, Fairey AS (2005) A longitudinal study of exercise barriers in colorectal cancer survivors participating in a randomized controlled trial. Annals of behavioral medicine : a publication of the Society of Behavioral Medicine 29 (2):147-153. doi:10.1207/s15324796abm2902_9

28. Jacobs LA, Shulman LN (2017) Follow-up care of cancer survivors: challenges and solutions. The Lancet Oncology 18 (1):e19-e29. doi:10.1016/S1470-2045(16)30386-2

29. Bower JE, Ganz PA, Desmond KA, Rowland JH, Meyerowitz BE, Belin TR (2000) Fatigue in breast cancer survivors: occurrence, correlates, and impact on quality of life. Journal of clinical oncology : official journal of the American Society of Clinical Oncology 18 (4):743-753.

doi:10.1200/JCO.2000.18.4.743

30. Goldstein D, Bennett BK, Webber K, Boyle F, de Souza PL, Wilcken NR, Scott EM, Toppler R, Murie P, O'Malley L, McCourt J, Friedlander M, Hickie IB, Lloyd AR (2012) Cancer-related fatigue in women with breast cancer: outcomes of a 5-year prospective cohort study. Journal of clinical oncology : official journal of the American Society of Clinical Oncology 30 (15):1805-1812.

doi:10.1200/JCO.2011.34.6148

31. Sandler CX, Goldstein D, Horsfield S, Bennett BK, Friedlander M, Bastick PA, Lewis CR, Segelov E, Boyle FM, Chin MTM, Webber K, Barry BK, Lloyd AR (2017) Randomized evaluation of cognitive- 
behavioral therapy and graded exercise therapy for post-cancer fatigue. Journal of pain and symptom management. doi:10.1016/j.jpainsymman.2017.03.015

32. Brown JC, Huedo-Medina TB, Pescatello LS, Pescatello SM, Ferrer RA, Johnson BT (2011) Efficacy of exercise interventions in modulating cancer-related fatigue among adult cancer survivors: a metaanalysis. Cancer epidemiology, biomarkers \& prevention : a publication of the American Association for Cancer Research, cosponsored by the American Society of Preventive Oncology 20 (1):123-133. doi:10.1158/1055-9965.EPI-10-0988

33. Fitzgerald B (2007) Review: regular exercise improves quality of life and physical fitness in women with breast cancer. Evidence-based nursing 10 (1):12. doi:10.1136/ebn.10.1.12

34. McNeely ML, Campbell KL, Rowe BH, Klassen TP, Mackey JR, Courneya KS (2006) Effects of exercise on breast cancer patients and survivors: a systematic review and meta-analysis. CMAJ : Canadian Medical Association journal = journal de l'Association medicale canadienne 175 (1):34-41. doi:10.1503/cmaj.051073

35. Rogers LQ, Courneya KS, Anton PM, Verhulst S, Vicari SK, Robbs RS, McAuley E (2016) Effects of a multicomponent physical activity behavior change intervention on fatigue, anxiety, and depressive symptomatology in breast cancer survivors: randomized trial. Psycho-oncology.

doi:10.1002/pon.4254

36. Gothe NP, Kendall BJ (2016) Barriers, Motivations, and Preferences for Physical Activity Among Female African American Older Adults. Gerontology \& geriatric medicine 2:2333721416677399. doi:10.1177/2333721416677399

37. Perry RA, Daniels LA, Bell L, Magarey AM (2017) Facilitators and Barriers to the Achievement of Healthy Lifestyle Goals: Qualitative Findings From Australian Parents Enrolled in the PEACH Child Weight Management Program. Journal of nutrition education and behavior 49 (1):43-52 e41. doi:10.1016/j.jneb.2016.08.018

38. Bourke L, Homer KE, Thaha MA, Steed L, Rosario DJ, Robb KA, Saxton JM, Taylor SJ (2013) Interventions for promoting habitual exercise in people living with and beyond cancer. The Cochrane database of systematic reviews 9 (9):CD010192. doi:10.1002/14651858.CD010192.pub2

39. Matson-Koffman DM, Brownstein JN, Neiner JA, Greaney ML (2005) A site-specific literature review of policy and environmental interventions that promote physical activity and nutrition for cardiovascular health: what works? American journal of health promotion : AJHP 19 (3):167-193 40. Ries AV, Yan AF, Voorhees CC (2011) The neighborhood recreational environment and physical activity among urban youth: an examination of public and private recreational facilities. J Community Health 36 (4):640-649. doi:10.1007/s10900-010-9355-1

41. Hansen $D$, Dendale $P$, van Loon $L$, Meeusen $R$ (2010) The impact of training modalities on the clinical benefits of exercise intervention in patients with cardiovascular disease risk or type 2 diabetes mellitus. Sports medicine (Auckland, NZ) 40 (11):921-940. doi:10.2165/11535930000000000-00000

42. Toohey K, Pumpa KL, Arnolda L, Cooke J, Yip D, Craft PS, Semple S (2016) A pilot study examining the effects of low-volume high-intensity interval training and continuous low to moderate intensity training on quality of life, functional capacity and cardiovascular risk factors in cancer survivors. PeerJ 4:e2613. doi:10.7717/peerj.2613

43. Schmitt J, Lindner N, Reuss-Borst M, Holmberg HC, Sperlich B (2016) A 3-week multimodal intervention involving high-intensity interval training in female cancer survivors: a randomized controlled trial. Physiological reports 4 (3). doi:10.14814/phy2.12693

44. Stonerock GL, Blumenthal JA (2017) Role of Counseling to Promote Adherence in Healthy Lifestyle Medicine: Strategies to Improve Exercise Adherence and Enhance Physical Activity. Progress in cardiovascular diseases 59 (5):455-462. doi:10.1016/j.pcad.2016.09.003 45. Smith L, Croker H, Fisher A, Williams K, Wardle J, Beeken RJ (2017) Cancer survivors' attitudes towards and knowledge of physical activity, sources of information, and barriers and facilitators of engagement: A qualitative study. European journal of cancer care. doi:10.1111/ecc.12641 
46. Bluethmann SM, Vernon SW, Gabriel KP, Murphy CC, Bartholomew LK (2015) Taking the next step: a systematic review and meta-analysis of physical activity and behavior change interventions in recent post-treatment breast cancer survivors. Breast cancer research and treatment 149 (2):331342. doi:10.1007/s10549-014-3255-5

47. Eakin EG, Lawler SP, Winkler EA, Hayes SC (2012) A randomized trial of a telephone-delivered exercise intervention for non-urban dwelling women newly diagnosed with breast cancer: exercise for health. Annals of behavioral medicine : a publication of the Society of Behavioral Medicine 43 (2):229-238. doi:10.1007/s12160-011-9324-7

48. Liss MA, Schenk JM, Faino AV, Newcomb LF, Boyer H, Brooks JD, Carroll PR, Dash A, Fabrizio MD, Gleave ME, Nelson PS, Neuhouser ML, Wei JT, Zheng Y, Wright JL, Lin DW, Thompson IM (2016) A diagnosis of prostate cancer and pursuit of active surveillance is not followed by weight loss: potential for a teachable moment. Prostate cancer and prostatic diseases 19 (4):390-394. doi:10.1038/pcan.2016.28

49. Alfano CM, Day JM, Katz ML, Herndon JE, 2nd, Bittoni MA, Oliveri JM, Donohue K, Paskett ED (2009) Exercise and dietary change after diagnosis and cancer-related symptoms in long-term survivors of breast cancer: CALGB 79804. Psycho-oncology 18 (2):128-133. doi:10.1002/pon.1378 50. Lim JW, Gonzalez P, Wang-Letzkus MF, Baik O, Ashing-Giwa KT Health behavior changes following breast cancer treatment: a qualitative comparison among Chinese American, Korean American, and Mexican American survivors. Journal of Health Care for the Poor \& Underserved 24 (2):599-618

51. Strasser B, Steindorf K, Wiskemann J, Ulrich CM (2013) Impact of Resistance Training in Cancer Survivors: A Meta-Analysis. Medicine \& Science in Sports \& Exercise 45 (11):2080-2090 2011p. doi:10.1249/MSS.0b013e31829a3b63

52. Hardee JP, Porter RR, Sui X, Archer E, Lee IM, Lavie CJ, Blair SN (2014) The effect of resistance exercise on all-cause mortality in cancer survivors. Mayo Clinic Proceedings 89 (8):1108-1115 1108p. doi:10.1016/j.mayocp.2014.03.018

53. Mishra SI, Scherer RW, Geigle PM, Berlanstein DR, Topaloglu O, Gotay CC, Snyder C (2012) Exercise interventions on health-related quality of life for cancer survivors. The Cochrane database of systematic reviews 8 (8):CD007566. doi:10.1002/14651858.CD007566.pub2

54. Mutrie N, Campbell AM, Whyte F, McConnachie A, Emslie C, Lee L, Kearney N, Walker A, Ritchie $D$ (2007) Benefits of supervised group exercise programme for women being treated for early stage breast cancer: pragmatic randomised controlled trial. BMJ (Clinical research ed) 334 (7592):517. doi:10.1136/bmj.39094.648553.AE

55. Souto RQ, Khanassov V, Hong QN, Bush PL, Vedel I, Pluye P (2015) Systematic mixed studies reviews: updating results on the reliability and efficiency of the Mixed Methods Appraisal Tool. International journal of nursing studies 52 (1):500-501. doi:10.1016/j.ijnurstu.2014.08.010 56. Sandelowski M, Voils Cl, Knafl G (2009) On Quantitizing. Journal of mixed methods research 3 (3):208-222. doi:10.1177/1558689809334210

57. Sandelowski M (2001) Real qualitative researchers do not count: the use of numbers in qualitative research. Res Nurs Health 24 (3):230-240

58. O'Cathain A, Thomas KJ, Drabble SJ, Rudolph A, Goode J, Hewison J (2014) Maximising the value of combining qualitative research and randomised controlled trials in health research: the QUAlitative Research in Trials (QUART) study--a mixed methods study. Health technology assessment (Winchester, England) 18 (38):1-197, v-vi. doi:10.3310/hta18380 